This is an Accepted Manuscript of an article published by Taylor \& Francis in the Journal of Marketing Management online on Septe mber 6, 2016, available online: http://www.tandfonline.com/doi/full/10.1080/0267257X.2016.1229688

\title{
Design and the creation of meaningful consumption practices in access-based consumption
}

Adèle Gruen

- Institute of Management Studies, Goldsmiths, University of London

- $\quad+44(0) 202964220$

- a.gruen@gold.ac.uk

Biographical note:

Adèle Gruen is a Lecturer of Marketing at Goldsmiths, University of London. She is completing a $\mathrm{PhD}$ in consumer research at Université Paris-Dauphine, France. Her doctoral research focuses on consumers' practices in contexts of access-based consumption. She is interested in the role that design plays in the enactment of these practices. 


\begin{abstract}
:
Within the rising access economy, products that were traditionally owned are now accessed, shared, rented or swapped. A recent research has shown that access-based consumption, when consumers pay a fee to have access to a product or service, threatens the relationship between consumers and objects. Specifically, access prevents consumers from enacting practices of appropriation and from gaining anything other than utility from this type of consumption. To address this issue, this research draws on the discipline of design and the theory of practice to examine how users form relationships with objects they use. Design, by changing consumer practices, could be the key in restoring the relationship between users and accessed objects. This article looks at a Parisian car sharing system to understand the role of design in restoring this relationship.
\end{abstract}

Keywords: access-based consumption; design; practice theory; car sharing

Summary statement of contribution:

Previous research on access economy and car sharing indicates that consumers do not construct a relationship with objects in this context. This article aims to understand the role of design in restoring this relationship through the activation of meaningful practices. The research looks at consumers' practices of appropriation of cars in Autolib', a French car sharing scheme. Underpinned by practice theory and design research, this paper illustrates how specific design elements enable practices of appropriation of accessed vehicles through controlling, knowing and creating the product and the service. 


\section{Design and the creation of meaningful consumption practices in access-based consumption}

\section{Introduction}

Can design change the practices of access-based consumption? Access encompasses 'transactions that may be market-mediated, in which no transfer of ownership takes place' (Bardhi \& Eckhardt, 2012, p. 1). Consumers have access to goods or services in exchange for a fee. Bardhi and Eckhardt (2012) studied the car sharing system Zipcar in Boston, Massachusetts, and find that Zipcar consumers use the system only for utilitarian purpose. They do not engage in specific practices to transform this use value into sign value. Consumers' lack of identification with the accessed cars explains this lack of meaning. Specifically, short-term duration of access, anonymity of the use of the service and market-mediation prevent users from incorporating the accessed car to their extended selves (Bardhi \& Eckhardt, 2012; Belk, 1988). This has strong implications for the consumer-object relationship in access contexts. This research aims to answer Bardhi and Eckhardt's call to 'examine access contexts in which identity and the hedonic value of the object are more salient' (2012, p. 16). In order to so, we turn to design research.

Design research is concerned with the development of artefacts and user practices. It is interested in signs, things, actions and thoughts (Buchanan, 1992), as well as in the user, the object and the use (Dubuisson \& Hennion, 1996). This vision of design integrating the user, the technology (product or service), and the relationship between them is grounded in science and technology studies (STS). STS is concerned with the social, cultural and technical aspects of an innovation (Akrich, 1992). To understand these cultural changes, we need to examine an object's 
circuit of culture (Du Gay, Hall, Janes, Madsen, Mackay \& Negus, 2013). This involves studying an object's representation, identity, production, consumption and regulation. Designers can force a change in consumption practices by creating new artefacts. This change in practices leads to the development of new representations and meanings attached to the object. This link between design and consumption practices shows the chain of meaning created by design (Du Gay et al., 2013).

This paper studies a car sharing system in which design plays an important role. Zipcar has no specific design project. For example, there is no uniformity in their fleet of cars (Bardhi \& Eckhardt, 2012). The present research focuses on the car sharing system Autolib' ${ }^{\circledR}$ in Paris, France. Autolib's fleet consists of one model of vehicle, the Bluecar®, designed by Pininfarina, the designer of Ferrari. The aim of this paper is to understand how a design project can foster user practices of appropriation in an access context. Practices of appropriation are important to enable users to create new representations and meanings (Arsel \& Bean, 2013; Du Gay et al., 2013; Magaudda, 2011; Reckwitz, 2002a, 2002b). Can design, through the creation of new appropriation practices, create meanings for consumers in a context of access-based consumption?

The literature section first builds on Bardhi and Eckhardt (2012) to identify a theoretical gap between access-based consumption and design. Second, it provides insights in the link between STS, design, and the chain of meaning and practice theory (Arsel \& Bean, 2013; Du Gay et al., 2013; Fallan, 2008; Silverstone \& Haddon, 1996). Third, it focuses on appropriation as a practice, in a consumer research perspective (Belk, 1988; Magaudda, 2011; Reckwitz, 2002b; Sartre, 1943-1984). The next sections present the context of this study and the research question and describe the research method and the findings. The findings deconstruct the practices of 
appropriation and look at key design elements and their role in the enactment of these practices. The paper concludes with a discussion of the findings, the limitations of the study, and proposes avenues for future research.

\section{Literature review}

\section{Access-based consumption}

The recent rise in collaborative forms of consumption such as access and sharing invites us to reexamine the consumer-object relationship. The role of consumption as a possession-based activity allowing consumers to build identity(ies) has long been studied in marketing (Ahuvia, 2005; Belk, 1988; Firat \& Venkatesh, 1995; Richins, 1994). However, this has recently been disrupted by the emergence of the sharing economy (Botsman \& Rogers, 2010; John, 2013). Firms like Airbnb, Couchsurfing, and BlablaCar have millions of users. Collaborative consumption can be seen as a new consumption phenomenon. However, Felson and Spaeth first used the term in 1978 to describe joint activities of consumption. The sharing of goods, experience, time and care among family members, neighbourhoods or communities members is not new (Price, 1975; Sahlins, 1972). Yet, in the last decade, the scale of these consumption modes has expanded beyond families and neighbourhoods due to the rise of the Internet (Belk, 2014; Botsman \& Rogers, 2010). Consumers, who are geographically apart, can now swap, share and exchange goods or services in a click. A new focus has emerged in consumer research in the contexts of the sharing economy (Belk, 2007, 2010, 2014; Lamberton \& Rose, 2012; Ozanne \& Ballantine, 2010), mutuality 
(Arnould \& Rose, 2015) and access-based consumption (Bardhi \& Eckhardt, 2012; Chen, 2009; Eckhardt \& Bardhi, 2016; Lawson, Gleim, Perren \& Hwang, 2016).

Access differs from sharing and ownership on several dimensions. First, access encompasses transactions in which no transfer of ownership takes place. A third party owns the object of consumption and consumers do not become owners of the object. In the case of sharing (Belk, 2010), the ownership of the object is shared jointly by consumers. Belk (2010) distinguishes between sharing in, which qualifies sharing behaviours existing in close, intimate circles such as family or friends; and sharing out, which is when sharing happens outside of the extended self of the individual. The case of ownership is different in that there is a special relationship between consumers and their possessions, involving the integration of objects into their extended self (Belk, 1988). Ownership also results in obligations and privileges for consumers towards the object (Belk, 1988).

Bardhi and Eckhardt (2012) developed six dimensions of access-based consumption: temporality, anonymity, market mediation, consumer involvement, type of accessed object and political consumerism. The authors study the context of car sharing and characterise it as 'longitudinal, frequently dormant access of limited duration; close to home and anonymous; market mediated; self-service; and based on a more functional and material object.' (Bardhi \& Eckhardt, 2012, p. 5). The authors ground their research in Boston, Massachusetts with a case study of Zipcar consumers. Zipcar members have access to a fleet of cars. Cars are parked close to users' residence or place of work. Members can rent a car by the hour or for the day in a system of loop circuit: they have to return the car to its permanent parking space at the end of the rental 
period. Zipcar possesses a fleet of about 30 models. There is no uniformity in the cars they offer: they range from the most basic models to green hybrid models and luxury brands. Bardhi and Eckhardt (2012) find that the relationship between Zipcar consumers and the accessed cars is utilitarian. Zipcar members use the service for its use value. This finding contrasts with the ecological and trendy image of car sharing in society. Zipcar members do not engage in practices to transform this use value into sign value. This means that users do not create any relationship with the vehicle. They do not identify with it nor do they appropriate it. Bardhi and Eckhardt (2012) report that this lack of relationship results from short duration of access, anonymity and market mediation. These dimensions prevent users from incorporating accessed cars to their extended selves (Belk, 1988). For example, users do not take the time to adapt the car to their preferences by changing the radio. The duration of use is not long and it does not seem necessary (Bardhi \& Eckhardt, 2012, p. 9). Feeling of contagion and negative reciprocity also play a role. Feeling of contagion occurs when consumers feel disgust when they are aware that someone else physically touched an object (Argo, Dahl \& Morales, 2006); users do not identify with other users. Negative reciprocity occurs when consumers engage in the exchange of goods only in self-interest; they feel no responsibility towards the company or the cars. In sum, in the context of car sharing, users do not engage with the object, the service or the company beyond use value. Bardhi and Eckhardt (2012) do not question the extent to which the design of the product and service plays a role. The chain of meaning shows the importance of design in creating meanings for consumers (Du Gay et al., 2013).

\section{Design and the chain of meaning}


Implementing a design project implies thinking about the product itself but also about the actors of the object (the users), and the situation of usage (the consumption context) (Dubuisson \& Hennion, 1996; Findeli \& Bousbaci, 2005; Vial, 2015). The discipline of design is concerned with 'the accomplishment of [human beings'] individual and collective purposes' (Buchanan, 2001, p. 9). Design research links insights from social sciences with the development of new products and product features (Buchanan, 2001). Marketing practitioners often depict design as a mere product development activity (Beverland \& Farrelly, 2011). For designers, marketing is often too concerned with cost and managerial issues to be interesting. This situation creates misunderstanding between the two disciplines (Beverland \& Farrelly, 2011). Yet when they work hand in hand, they can achieve interesting results (Beverland \& Farrelly, 2011; Bruce \& Daly, 2007). Design is a discipline that integrates elements from production to distribution, from consumption to waste and from demography to consumer culture (Julier, 2014). Science and technology studies is a multidisciplinary field of research concerned with the role of innovation and design in the development of social relationships (Sismondo, 2011; Woolgar, 1991). Technologies, objects and innovations are pivotal in daily lives of consumers. The design of these technologies shapes consumers practices and social interactions (Sismondo, 2011). At the same time, technologies are socially constructed. The development of a new product is indeed a long process involving numerous actors (Akrich, 1987, 1992; Fallan, 2008; Silverstone \& Haddon, 1996). Fallan (2008) encourages researchers to study the script of an artefact to understand 'how producers/ designers, products, and users negotiate and construct a sphere of action and meaning' (Fallan, 2008, p. 63). STS considers objects as non-human actors (Akrich, 1987, 1992; Akrich, Callon \& Latour, 2006; Law, 2009) who 'act as mediators, transforming meaning as they form and 
move through networks' (Fallan, 2008, p. 62). The physical aspect of technologies requires special attention to grasp the consequences it has on the structuration of social relationships and individual practices.

Du Gay et al. (2013) propose the concept of the chain of meaning to link the development of a new product to the creation of meaning. Taking the example of the Walkman®, they describe how designers force the movement of cultural practices via new artefacts. New technologies change the way consumers interact with the product, and change their gestures, actions and movements. In turn, these new practices associated with the artefact create new representations. Through the use of sign and language, representations construct new meanings upon which consumers build new identities. Du Gay et al. (2013) show how the Walkman became part of the identity of the young urban nomad through development of new practices of listening to music outside the home. This idea of design as the starting point of the creation of meaning through practices shows that the theory of practice and science and technology studies are somehow intertwined (Reckwitz, 2002a). Both reject the ideas of a rational homo economicus and of a homo sociologicus, which 'explains actions by pointing to collective norms and values' (Reckwitz, 2002 b, p. 245). For practice theory, consumers are 'agents bounded by socioculturally constituted nexuses' (Arsel \& Bean, 2013, p. 901). A STS's view of practice differs from a sociologist's view like Bourdieu's $(1977,1990)$ in that it includes non-humans actors such as artefacts in the activity of practice (Magaudda, 2011; Reckwitz, 2002a; Shove \& Pantzar, 2005).

\section{Appropriation as practice}


Appropriation is a concept that contains different meanings depending on the context in which it is used. For musicians, appropriation refers to the borrowing of another musician's elements in the creation of a new piece (Born \& Hesmondhalgh, 2000). This concept is close to the anthropological concept of cultural appropriation (cultural borrowing), which is closely related to assimilation. Cultural appropriation is the adoption of elements of a different culture (Ziff \& Rao, 1997). Design researchers within STS study appropriation in relation to the adoption of new technology (Silverstone \& Haddon, 1996). Appropriation encompasses the actions users undertake to integrate the objects in the home (Silverstone \& Haddon, 1996; Silverstone \& Morley, 1992). Finally, in consumer research, appropriation refers to actions through which consumers make something theirs: objects (Belk, 1988; Pierce, Kostova \& Dirks, 2001), stores (Aubert-Gamet, 1997; Bonnin, 2002), experiences (Carù \& Cova, 2006) or services (Mifsud, Cases \& N'Goala, 2015).

These different perspectives have in common a dynamic view of appropriation. Appropriation implies actions from individuals who wish to make something theirs. In this sense, appropriation is a practice. A practice is 'a routinized way in which bodies are moved, objects are handled, subjects are treated, things are described, and the world is understood' (Reckwitz, 2002b, p. 250). Practice theory understands consumption through the analysis of daily routines between consumers, objects, and the environment (Shove \& Pantzar, 2005). Practices are about objects (technology and material culture in general), doings (competences and activities) and meanings (Arsel \& Bean, 2013; Magaudda, 2011). Consumers engage in activities with objects in order to produce meanings. The concept of appropriation is close to that of perceived ownership. Perceived ownership is 'that state in which individuals feel as though the target of ownership (material or 
immaterial in nature) or a piece of it is "theirs" (i.e., "It is MINE!")' (Pierce et al., 2001, p. 299). Simply touching an object contributes to a perceived sense of ownership (Peck \& Shu, 2009). Touching relates to appropriation: it is an action (a 'doing') resulting in the feeling that the object is 'mine' (meaning is attributed to the object). Appropriation is thus a set of practices through which consumers achieve perceived ownership of an object, a place, or a service. These set of practices, or 'routes' to reach perceived ownership are threefold: knowing intimately, controlling and creating (Belk, 1988; Pierce et al., 2001). They originate from Jean-Paul Sartre's ways of having (1943). To Sartre (1943), wanting to have an object means wanting to be in a relationship with this object. Sartre does not write of practices, yet he refers to activities done with objects in order to be. This reveals the three dimensions of the circuit of practice: doings, objects and meanings (Magaudda, 2011). Consumers engage in practices of appropriation to create relationships with the objects they use. Sartre (1943) identifies three appropriation practices: creating (making something to possess it), knowing (knowing something intimately contributes to its existence for me) and controlling (being able to use, destroy or modify the object). Belk (1988) adds a fourth appropriation practice, which he identifies as symbolic contamination. Contamination is a passive form of appropriation, and in this regard differs from the three other practices. Contamination occurs by involuntarily incorporating others into one's extended self (Argo, Dahl \& Morales, 2006).

In access-based consumption, the question of appropriation is crucial (Bardhi \& Eckhardt, 2012). Appropriation of accessed objects and services could lead to perceived sense of ownership through the creation of representations and meanings for consumers. Creating a perceived sense 
of ownership encourages consumers to care for the accessed objects. Indeed, when an object belongs to one's extended self, the consumer takes greater care of it (Belk, 1988).

\section{Car sharing in Paris, Autolib' and the research question}

Cars are traditionally owned objects that play a strong part in consumers' extended selves (Belk, 1988). It has been the object of extended research in marketing, especially in the case of social identity such as brand communities (Cova, Kozinets \& Shankar, 2012; McAlexander, Schouten, \& Koenig 2002; Muniz \& O'Guinn, 2001). Car sharing in France is successful, especially sharing between individuals: Blablacar, a French company, is leader in this sector and reached 10 million members worldwide in 2014. Car sharing schemes are spreading in many French cities such as Lyon, Paris and Bordeaux. French cities, especially Paris, seem to offer a fertile ground for car sharing. In Paris most inhabitants do not own a car. In 2011, 64\% of Parisians used mainly public transport to go to work and only 15\% drove a car (Insee, 2015). When Bardhi and Eckhardt (2012) conducted their study on the car sharing system Zipcar, they noticed that Zipcar was the first market-mediated access service in Boston. Consumers were not used to this type of service when it was first launched. In Paris, inhabitants had experienced access before car sharing. Vélib', a selfservice bike-sharing system, has offered bikes in free access for a small fee since 2007. In 2011, it had an average daily ridership of around 85,000. The popularity of Vélib' paved the way for the car sharing system Autolib'. In French, Vélib' is a mix of the words bike (vélo) and freedom (liberté). Autolib' followed that by combining automobile and liberté. When Autolib' was launched, four years after Vélib', every Parisian was already familiar with the service: Vélib', but with cars. Another cultural element that favours the integration of Autolib' in Paris is the structure 
of the city's streets. The streets are narrow by comparison to the US with many small vehicles including scooters, bikes, compact cars and two-seater electrical cars such as Renault's Twizy®. Autolib's cars are small and grey and fit perfectly in the Parisian landscape.

Autolib' is a public service company run by the Bolloré group. It was launched in 2011 and today has around 4,000 cars and more than 900 charging stations. In 2015, it had 75 thousand users in Paris and its suburbs. Autolib', like Zipcar, is, 'longitudinal, frequently dormant access of limited duration; close to home and anonymous; market mediated; self-service' (Bardhi \& Eckhardt, 2012, p 5). However, Autolib' and Zipcar differ in the type of accessed object they offer. Zipcar offers a functional and material object (Bardhi \& Eckhardt, 2012). All the cars are different: there is no uniformity or design involved. In contrast, Autolib' only has one model, the Bluecar, designed by Pininfarina for the Bolloré group. The cars were then adapted so they could be used for daily use by different drivers. The doors and the seat structure were reinforced. The Bluecar is $100 \%$ electric and has automatic transmission, two features that are not yet common in France. It is equipped with an on-board computer that gives users access to all kinds of information related to the smooth running of the car, as well as GPS, FM radio, and a button to contact the call centre in case of an emergency. There are several subscription packages but the Autolib' Premium plan costs $€ 120$ a year for access to a car $24 / 7$, with unlimited reservations for both car and parking place, and $€ 6$ for every half-hour trip. In February 2016, Autolib’ launched a new subscription package called Ready to Drive. Subscription is free but the hourly rate is higher (€9 per half-hour). Users can book the nearest available car via an app on their smartphone. They then go to the charging station to pick up the vehicle. Autolib' users can return the car at any charging station of 
their choice, whereas Zipcar users have to return the car to its home location. The uniformity of Autolib's fleet, the design of the Bluecar by Pininfarina, and the adaption made to the car show the strong design attitude of the company. Bluecars are associated with Autolib'. When you see a Bluecar in the streets of Paris, you can be certain the driver is an Autolib' member. Due to these product and service design features, questions of 'identity and the hedonic value of the [accessed] object' (Bardhi \& Eckhardt, 2012. p. 16) are expected to be more salient in Autolib'. Our main research question is: Can design, through the creation of new appropriation practices, create meanings for consumers in the context of access-based consumption? This unfolds into two further questions: Can the design project embedded in Autolib' create user appropriation practices with accessed cars? If so, do these practices contribute to the creation of meanings for consumers?

\section{Method}

This research focuses on practices of appropriation of accessed objects. The aim is to understand the role of design in the enactment of the practices and in the creation of meanings. A qualitative methodology is adopted, coherent with the comprehensive nature of the research question. Studying access is relatively new in marketing research, which is why I adopted an inductive approach (Fischer \& Otnes, 2006). Throughout data collection, I referred to the literature to order the findings, while allowing new insights to emerge from the field (Strauss \& Corbin, 1990). I collected data at two different times. I conducted 13 interviews with Autolib' users in Paris and its close suburbs (see Table 1.). An analysis of the interviews indicated that later interviews did not generate any new ideas and that no further information would be collected with a larger number of interviews. Previous research studying consumer practices and experiences were successful in 
interpreting smaller sample sizes (Bonsu \& Belk, 2003; Holt, 2002; Fournier, 1998; Thompson, 1996). Like Zipcar users (Bardhi \& Eckhardt, 2012), Autolib' users are young, professional and urban (Ademe, 2014). The sample consists of seven men and six women, all between the ages of 20 and 32. Nine of them are young professionals and four are university students. The sample is consistent with the demographic profiles of Autolib' users. I contacted users through word-ofmouth or recruited them directly at Autolib' stations. Each interview lasted between forty and seventy minutes. The discussions focused on sharing in general, on the relationship with the company' and on the Bluecar itself. The second part of the data collection comprised observations and an interview with an Autolib' manager. This was done to bring depth to the interviews by observing practices that were described in the first round of data collection. Practices are activities done with objects, which is why it was important to combine interviews with onsite observations of Autolib' users. I accompanied two informants for an hour each to observe their practices with the Bluecar from the moment they booked the car to the moment they returned it. I also observed users at charging stations. I made five videos and took twelve photos throughout the process. Finally, I conducted an interview with a high-ranked manager at Autolib', which lasted an hour and a half. This interview allowed me to triangulate the data and to understand the history and context of the company, its future projects, and the company's point of view on design. 
Table 1. Informant demographic characteristics

\begin{tabular}{|c|c|c|c|c|}
\hline Name & Age & Profession & Place of residence & User for \\
\hline Carla & 27 & Student & Suburbs & 6 months \\
\hline Marianne & 25 & Intern & Paris & 2 years \\
\hline Olivier & 27 & Consultant & Paris & 4 months \\
\hline Tristan & 22 & Intern & Paris & 1.5 years \\
\hline Johanna & 26 & Student & Paris & 2.5 years \\
\hline Jean-Marc & 31 & Employee & Paris & 1.5 years \\
\hline Lionel & 29 & Engineer & Suburbs & 2.5 years \\
\hline Jean-Baptiste & 28 & Engineer & Paris & 7 months \\
\hline Mélissa & 23 & Student & Suburbs & 6 months \\
\hline Christophe & 30 & Engineer & Suburbs & 1.5 years \\
\hline Gaëlle & 32 & Employee & Paris & 2 years \\
\hline Sacha & 20 & Student & Paris & 10 months \\
\hline Valérie & 27 & Lawyer & Suburbs & 1 months \\
\hline Alexandre (round 2) & 28 & Consultant & Paris & 9 months \\
\hline Julie (round 2) & 28 & Teacher & Paris & 3 years \\
\hline
\end{tabular}


I categorised the interviews transcripts both deductively (appropriation as an existing concept) and inductively to identify emerging themes (Spiggle, 1994). Guided by the constant comparative method of analysis, I compared each incident in the data with other incidents of the same category in order to identify similarities and differences (Spiggle, 1994). The analysis focussed on understanding the appropriation practices and the relationship with the Bluecar and the service. Specifically, I identified key design features involved in the appropriation practices. This analysis was then coupled with the observational data (interview transcripts, videos, pictures and field notes).

\section{Findings}

Introduction: a perceived sense of ownership

In accordance with Bardhi and Eckhardt (2012), the main reason that motivates consumers to subscribe to Autolib' is utilitarian. It is a practical service and that is why it is used. However, our findings also indicate that utilitarian value is not the only value users get from using the service. Indeed, in contrast to Bardhi and Eckhardt's (2012) findings that Zipcar users have no engagement with the car, Autolib' users seem to experience a perceived sense of ownership (Pierce et. al, 2001). The informants express the feeling that the cars they use are theirs. Johanna, a Parisian student who has been using the service for over two years, clearly states:

Yes, when I'm in the car, I switch on the music and I feel like I'm in my car. I don't feel as though I'm in someone else's car. I'm settled, once I've adjusted all the settings, I start the engine of and I really have the feeling of being in my car. [...] I'm in control, it's my 
car. I adjust the car to my settings, I do my things, I'm in charge, I drive the car... it's my car. (Johanna, 26)

Johanna expresses a feeling of perceived ownership over the Bluecar: 'I feel like I'm in my car'. This feeling seems to emerge from several of her own actions: 'I put the music on'; 'I've adjusted all the settings'; 'I am in control'; 'I'm in charge, I drive the car'; 'I adjust the car to my settings'; 'I do my things'. All these actions, these activities done in the car result in one feeling: 'it's my car'. Thus, utility is not all there is to the relationship between users and Autolib' cars. Johanna's words show her feeling of ownership. In the next sections, I examine the route that leads to this feeling by deconstructing consumer practices of appropriation. For each of the appropriation practices, i.e. controlling, knowing and creating (Belk, 1988; Sartre, 1943), I identify key design features that enable them and look for the meanings and representations that are created through these practices. I begin with the practice of controlling, which is enabled by two design elements: the electrical engine and the automatic transmission of the vehicle. These two features create a game-like sensation when driving the Bluecar. I then move to the practice of knowing, which is enabled by the uniformity of the vehicles' design and personalisation. Uniformity allows for ritualisation and the creation of habits, whereas personalisation creates emotional bonds. Finally, the design of the service enables the practice of creating by making users invest time and energy in the service.

\section{Controlling}


Practices of appropriation via controlling is enabled by Autolib's choice to offer only electric and automatic vehicles. Appropriation by control implies overpassing a difficulty or mastering the matter (Belk, 1988; Brunel \& Roux, 2006; Sartre, 1943). Materiality is important. Control happens when one has a strong hold over an object. This notion of control is apparent from Olivier's reaction. He is a Parisian consultant who has been using Autolib' for four months:

It may be the electrical aspect. The electrical aspect makes it bland; it's a piece of metal... But it's pretty funny because it's you who's in control, there's no engine, no machine ready to dominate. It's there and it works. There's a real feeling of possession (Olivier, 27)

Olivier expresses the power he feels over the vehicle, which runs on an electric motor and has an automatic gearbox. Both of these features are not common in France: adopting them changes the practice of driving. Electric cars are quieter than conventional internal combustion engine cars, which produce noise and petrol fumes. Olivier feels that the car is somehow hiding to give full space for the user. He feels in control over the vehicle. Driving a Bluecar is smooth and quiet. The car is domesticated and not 'ready to dominate' (Olivier). New ways of doing with the object are created through the implementation of these two specific design features. According to Sartre, one can appropriate something through 'sliding' (1943, p. 629). By sliding Sartre means a gentle touch over the matter without compromising oneself into it. For instance, hiking to the top of the mountain will not force a hiker to slide into the mountain; (s)he will simply stay on top of it. Yet a feeling of ownership occurs when reaching the top because the hiker is able to dominate the mountain. Sartre (1943, p 627-631) also gives examples of games and sports to explain the notion of sliding. Jean-Baptiste experiences this game-like sensation when he drives a Bluecar: 
It's interesting that the car's quite high, a bit like a $4 \times 4$, so that the driver's seat is quite high, higher than most other cars, and this reinforces the game-like sensation. (JeanBaptiste, 28)

Although the car is quite small and urban, the driver's seat is higher than usual, giving JeanBaptiste a feeling of control. Informants compared the small, silent and easily manoeuvrable Bluecar to a toy-car, and used words such as karting and bumper car to describe it. Users are empowered by the height of the driver's seat, which 'reinforces the game-like sensation' (JeanBaptiste). When playing games, consumers immerse themselves into an experience (Brown \& Cairns, 2004; Chen, 2007; Choi \& Kim, 2004), which leads to appropriation (Carù \& Cova, 2006) and the feeling of flow (Csikszentmihalyi, 1997).

Compared to a manual car, driving an automatic car appears to be easier and smoother. Many people find it difficult to drive manual cars and drivers feel they have to learn to domesticate them. A gas engine is said to 'roar' like a wild beast. This is not the case of the electric and automatic Bluecar. What Olivier and Jean-Baptiste express is that the route towards domestication of the object does not have to be very difficult. Bluecars seem to work collaboratively with users in order to allow practices of appropriation. Through their design features, the cars help users to feel in control. As a result, users easily tame them and float in them:

You feel that it's made to travel in the future, you feel like the car is teletransporting, really. And it really makes the sound of the future. It does viiiiooooouuuuuuuu. So I don't know 
how to explain... You really have the impression that the car's flying over... You don't feel anything. It's really smooth, you see. (Marianne, 25)

The notion of sliding is apparent in Marianne's quote. It is not something she does on her own: the car 'teletransports' her into the 'future'. Elements of design such as the electric engine and the automatic gearbox change the representations associated with the cars. The sound is different: 'it does viiiiooooouuuuuuuu'; the driving also is different: 'It's really smooth, you see'. The practice of driving changes, which creates new representations of the Bluecar as the 'car of the future'. Consumers can draw on this representation to see themselves as drivers of the cars of the future.

\section{Knowing}

Knowing is a practice of having, which in the case of Autolib', is enabled by the uniformity of the Bluecars design. Objects exist for users when they become aware of them (Belk, 1988; Sartre, 1943, 1984). Sartre develops the idea of the dissolution of the known object in the self and writes: 'The known is transformed into $m e$; it becomes my thoughts and thereby consents to receive its existence from me alone' (Sartre, 1984, p. 579). The known objects become parts of the individual's extended self (Belk, 1988). One of the design features that enables the practice of appropriation is the uniformity of Autolib's cars. Users recognise the Bluecar in the streets from afar, know the specificities associated with driving them and can describe the vehicles' interior. Because of this consistency in design, users can engage in daily routines with the vehicle. The same gestures are repeated every time they use the service. Reckwitz's (2002b) defines practices as 'routinized ways in which bodies are moved, objects are handled, subjects are treated, things 
are described and the world is understood'. This routinised movement of the body is enabled here by Autolib's decision to offer only one car model. Having a single model establishes the impression of always getting into the same car. Habits are created between the users, the cars and the service:

Yes, I'm very familiar [with the car]; I know that the first thing to do is to switch it on because the built-in computer can sometimes be slow. So, I switch it on to get it started and in the meantime I adjust the mirrors and the seat. I do it in that order. (Lionel, 29)

This quote illustrates the ritualised sequence performed by Lionel when he gets into the Bluecar. Once seated, he first switches on the built-in computer, then adjusts the mirrors and finally adjusts the seat. Rituals are 'meaningful aspects of both everyday and extraordinary human experience'; ‘expressive, symbolic activities' that are sequential and repeated over time (Rook, 1985). Autolib' users can describe the sequence of activities they do before starting the engine in precise details. I also observed this sequence of gestures during my observations. These rituals diverge slightly, but users feel the necessity to go through these rituals in a specific order to feel comfortable. Lionel's sentence 'I do it that order' shows how important this ritual is to him. If the order is changed, the ritual is not complete.

Designing smart technology in the context of access also appears important. The design of the built-in computer reinforces familiarity with the Bluecar. Its most important feature is the storage of favourite radios and destinations. When users get in the car, the radio stations are always the same as the previous time, just as if the car had been waiting for them: 
I arrive, it recognizes me so I've got all my stations on the GPS, everything is automatic. I don't have to search all the time, my radio is on. If we'd have to look for our favourite radio program every time, it wouldn't be as great. This way, it's true, it does feel as though it's more yours. (Mélissa, 23)

Here the built-in computer reduces the ritualisation: listening to her favourite radio does not require any action from Mélissa. The computer's design integrates parts of the ritual instead of the user. Zipcar users do not take the time to adjust the radio to their favourite stations and thus do not settle (Bardhi \& Eckhardt, 2012, p. 9). In Autolib', the computer performs its rituals (i.e., recognizes the user, says hello, remembers stored radio stations, and proposes favourite destinations) while users go through their installation rituals. The installation ritual thus appears to be a co-constructed process between the car, the computer, and the user. The co-construction of these rituals creates an emotional relationship between the user and the car:

Oh yes, I'm fond of it, I take my little car, I'm happy, I like driving Autolib'. It's practical because it's small, you can manage it easily, it's automatic... You arrive and your radio is already on because the car recognizes that it’s me: 'Hello Mélissa!' (Mélissa, 23)

Mélissa expresses attachment towards the vehicle ('I'm fond of it') and uses possessive pronouns ('I take my little car'). These elements of discourse show a perceived sense of ownership of the car. She builds a relationship with the car, and creates representations around it. The car is 'small', 'easy', 'automatic': a great urban car. The personalisation created by the design of the built-in computer is crucial. It creates an emotional bond between the car and the user (Mugge, 
Schoormans \& Schifferstein, 2009). The observations of users renting a Bluecar revealed the importance of the moment the radio is switched on. It marks the instant when everything is ok and ready to go.

\section{Creating}

Creating is the third practice of appropriation. In the case of Autolib', this practice is enabled by the design of the service, which forces users to invest time and energy. Sartre (1943) acknowledges that investing time, money and energy participates to the practice of appropriation via creation. In the case of Autolib', first, the perspective user needs to spend time and energy in researching the service and the subscription. 'It's really a peculiar process. You must really want to use them to try it out, you have to take a personal badge' (Tristan, 22). Looking for information about a product or service already contributes to its creation (Brunel \& Roux, 2006). Second, understanding how the system works takes time, as Mélissa reports:

You just have to understand the mechanisms. After a while, it becomes routine, but in the beginning it's a bit complicated and you have to understand how it works. You can't just pick up the car and drive off. You have to use your personal badge to unlock the car things like that. (Mélissa, 23)

It is interesting to see here that practices must be learnt before becoming routines activities. Practices become routine activities through their enactment. This is what Mélissa said. First, she had to 'understand the mechanisms', and only 'after a while' did it become automatic i.e. routine. This 'after a while' shows that the user needs to invest time for the enactment of appropriation. 
Specific gestures and movements have to be performed in order to use the service and these create habits between the user and the car. These habits are energy consuming for users:

I think everyone does pretty much the same. You scan your card, you enter your code $[\ldots]$ then your Bluecar starts flashing, you put your card on the detector to open the small shutter, you unplug and put back the electrical supply, you get into your car [...]. So I push all the buttons very, very quickly $[\ldots]$ and then there's a whole thing that remembers your radio stations, there's your GPS that starts up. You hurry to fasten [your seatbelt], you put the key in the thing and then you start the engine, very simply. Oh and there's all the adjustments to make, that kind of thing to adjust the seat. (Tristan, 22)

Tristan's quote illustrates the set of knowledge and skills users create when using the car. The user has to do several activities in order to be able to drive. These gestures, or activities (doings) are illustrated by all the verbs Tristan uses: 'scan', 'enter', 'put, 'unplug', 'put back', 'get into', 'push', 'hurry', 'fasten', 'put', 'start', 'make', 'adjust'. Users have to adapt to the design of the system. They cannot simply open the door, sit down, turn on the ignition and drive off, but must undertake a series of sequential, routine actions to start using the service. The design of the car and the service contributes to build users' practices of appropriation via creation.

\section{Discussion}

This research looks at the role of design in enabling consumers' practices of appropriation in the context of access-based consumption. The research answers Bardhi and Eckhardt's (2012) call to examine 'access contexts in which identity and the hedonic value of the object are more salient'. 
Specifically, the findings show that consumers of access-based consumption services can achieve perceived ownership of accessed objects when a design project is embedded in the core of the service. This research furthers the understanding of the consumer-object relationship in the context of access. In contrast to Zipcar users (Bardhi \& Eckhardt, 2012), Autolib' users retain more than just utilitarian value when using the service. New meanings are associated to driving Autolib': smooth and silent, ecological, Parisian, futuristic. This research contributes to the discussion between the disciplines of consumer research and design. Both focus on consumers (users) and their relationship with objects. While the number of research on product design in marketing journals is slowly increasing (Luchs \& Swan, 2011), the two fields do not collaborate easily (Beverland \& Farrelly, 2011). Research that combines both approaches contributes to narrow this gap.

The findings also contribute to the design literature on product service systems when objects are used by multiple users. This research is useful for companies in access-based consumption as it helps them in designing meaningful products and services. First, developing objects that force a change in the practices associated with the type of object can create meaning for users. In Autolib', the cars are electric and automatic, two features that were new for almost all our informants. Due to these design features, new meanings are attributed to the car such as the 'car of the future'. Second, uniformity in the design of the product is key in this context, as it enables users to engage in practices of appropriation through knowing the object. In particular, uniformity enables habits and familiarity between users and the accessed cars. Finally, when objects are shared, co-creation and personalisation of the service appear necessary to create 
emotional bond (Mugge, Schoormans \& Schifferstein, 2009). In Autolib', the role of the built-in computer is crucial in this regard. Because the on-board computer saves the user's favourite radio stations, users feel as though they always get the same car. Recommending designers to design both uniform and personalised products can seem paradoxical. On the one hand, I encourage designers to offer standardised, uniform products, and on the other hand, I acknowledge the importance of personalisation, i.e. adaptation. The findings suggest that the combination of a consistent product design with a personalised service design is crucial in the context of access.

It is interesting to look at the findings of the present study through the brand concept management framework developed by Park, Jaworski and MacInnis (1986). The authors identify three brand concepts: functional, symbolic and experiential. Zipcar can be identified as a functional brand (Bardhi \& Eckhardt, 2012), whereas Autolib' is a more symbolic brand. The findings contribute to creating connections between design and branding. Future research should examine the connections between design and branding in the context of access-based consumption. The role of design in defining a brand concept should be strong in the introductory, the elaboration and the fortification stages of a brand life cycle (Park, Jaworski \& MacInnis, 1986). Indeed, design research shows that design is a culture that should be integrated in all the stages of brand and product development (Julier, 2014).

This research has several limitations. First, the number of interviews is limited to identify variation in the findings among informants who are early-adopters of Autolib' and those who just started using the service. Second, the number of observations conducted in the field are limited. This provides opportunities for future research to study consumers' practices in access-based 
consumption. An ethnographic, longitudinal approach could look at the evolution of practices in car sharing over a longer time period.

The context of the study is Paris, France, which constitutes a fertile ground for Autolib'. First, Parisians were already used to accessing transportation modes when Autolib' started business. Second, Bluecars are small and grey and thus fit well in the busy Parisian urban landscape. In 2015, the Bolloré group launched Autolib' in Indianapolis, Indiana, and it is planning to launch its service in London in 2016 and in Singapore in 2017. The use of the service is expected to vary with different cultural contexts. In Indianapolis for instance, journeys are longer as consumers drive to the airport or to university campuses. Bluecars intended for the US market are made to cover longer distances. Their design has been modified: the car is heavier, longer and more robust. Further research should focus on the adoption of this Parisian car to different cultural contexts and city layouts.

It would be interesting to compare the appropriation practices of accessed objects and accessed places. Place attachment shares many characteristics with object attachment (Debenedetti, Oppewal \& Arsel, 2014; Kleine \& Baker, 2004). Both objects and places are central for the consumer's definition of self(Belk, 1988). For example, these dynamics could be examined in coworking spaces. The office is often assimilated to a 'home away from home' (Tian \& Belk, 2005). This feeling of homeyness (McCracken, 1989) could be disrupted in the case of coworking spaces, especially if coworkers do not have their own desk. Further research should investigate the practices of appropriation of hot desks in coworking spaces. The role of design in the enactment of these practices could be a key issue. 
Word count: 7406

\section{Disclosure statement}

The authors reported no potential conflict of interest. 


\section{References}

ADEME, Enquete sur l'autopartage en trace directe, May 2014, available at: http://www.ademe.fr/sites/default/files/assets/documents/enquete-autopartage-entrace-directe-201405.pdf

Ahuvia, A. C. (2005). Beyond the extended self: Loved objects and consumers' identity narratives, Journal of Consumer Research, 32(1), 171-184. DOI: 10.1086/429607

Akrich, M. (1987). Comment décrire les objets techniques? [How to describe technical objects?], Techniques \& Culture (No. 9, pp. 49-64).

Akrich, M. (1992). The de-scription of technical objects. Shaping Technology/Building Society, 205-224.

Akrich, M., Callon, M., \& Latour, B. (2006), Sociologie de la traduction : textes fondateurs [Sociology of translation: founding texts]. Presses des MINES.

Argo, J. J., Dahl, D. W., \& Morales, A. C. (2006). Consumer contamination: How consumers react to products touched by others, Journal of Marketing, 70(2), 81-94. doi: $\underline{\text { http://dx.doi.org/10.1509/jmkg.70.2.81 }}$

Arnould, E. J., \& Rose, A. S. (2015). Mutuality Critique and substitute for Belk's “sharing”. Marketing Theory, 1470593115572669, doi:10.1177/1470593115572669

Arsel, Z., \& Bean, J. (2013). Taste regimes and market-mediated practice. Journal of Consumer Research, 39(5), 899-917., DOI: 10.1086/666595 
Aubert-Gamet, V. (1997). Twisting servicescapes: diversion of the physical environment in a reappropriation process. International Journal of Service Industry Management, 8(1), 2641.

Bardhi, F., \& Eckhardt, G. M. (2012). Access-based consumption: The case of car sharing, Journal of Consumer Research, 39(4), 881-898. DOI: http://dx.doi.org/10.1086/666376

Belk, R. (1988). Possessions and the Extended Self, Journal of Consumer Research, Volume 15, Issue 2, 139-168

Belk, R. (2007). Why not share rather than own? The Annals of the American Academy of Political and Social Science, 611(1), 126-140. doi: 10.1177/0002716206298483

Belk, R. (2010). Sharing, Journal of Consumer Research, Volume 36, 715-734. DOI: $\underline{\text { http://dx.doi.org/10.1086/612649 }}$

Belk, R. (2014), You are what you can access: Sharing and collaborative consumption online, Journal of Business Research,67(8), 1595-1600., doi:10.1016/j.jbusres.2013.10.001

Beverland, M. B., \& Farrelly, F. J. (2011). Designers and Marketers: Toward a Shared Understanding, Design Management Review,22(3), 62-70. DOI: 10.1111/j.19487169.2011.00141.x

Bonnin, G. (2002). Magasin et expérience de magasinage: le rôle de l'appropriation. [Stores and store experience: the role of appropriation], Décisions Marketing, 65-75.

Bonsu, S. K., \& Belk, R. W. (2003). Do not go cheaply into that good night: Death-ritual consumption in Asante, Ghana. Journal of Consumer Research,30(1), 41-55. DOI: $\underline{\text { http://dx.doi.org/10.1086/374699 }}$ 
Born, G., \& Hesmondhalgh, D. (2000). Western music and its others: Difference, representation, and appropriation in music. University of California Press.

Botsman, R., \& Rogers, R. (2010). What's mine is yours: how collaborative consumption is changing the way we live. Collins.

Bourdieu, P. (1977). Outline of a Theory of Practice (Vol. 16). Cambridge University Press.

Bourdieu, P. (1990). The logic of practice. Stanford University Press.

Brown, E., \& Cairns, P. (2004, April). A grounded investigation of game immersion, CHI'04 extended abstracts on Human factors in computing systems, p. 1297-1300, ACM. Doi: $\underline{10.1145 / 985921.986048}$

Bruce, M., \& Daly, L. (2007). Design and marketing connections: creating added value. Journal of Marketing Management, 23(9-10), 929-953, DOI: 10.1362/026725707X250403

Brunel, 0., \& Roux, D (2006). L’appropriation des produits par le consommateur : proposition d'une grille d'analyse [Product appropriation by consumers: proposition for an analysis grid], dans Alcouffe, S. L'appropriation des outils de gestion: vers de nouvelles perspectives théoriques?. Université de Saint-Etienne.

Buchanan, R. (1992). Wicked problems in design thinking, Design Issues, 8(2), 5-21. DOI: $10.2307 / 1511637$

Buchanan, R. (2001). Design research and the new learning, Design Issues,17(4), 3-23. doi:10.1162/07479360152681056

Carù, A., \& Cova, B. (2006). How to facilitate immersion in a consumption experience: Appropriation operations and service elements. Journal of Consumer Behaviour, 5(1), 4-14. DOI: $10.1002 / \mathrm{cb} .30$ 
Chen, J. (2007). Flow in games (and everything else). Communications of the ACM, 50(4), 31-34.

Doi: $10.1145 / 1232743.1232769$

Chen, Y. (2009). Possession and access: Consumer desires and value perceptions regarding contemporary art collection and exhibit visits. Journal of Consumer Research, 35(6), 925-940., DOI: http://dx.doi.org/10.1086/593699

Choi, D., \& Kim, J. (2004). Why people continue to play online games: In search of critical design factors to increase customer loyalty to online contents, CyberPsychology \& Behavior, 7(1), 11-24. doi:10.1089/109493104322820066.

Cova, B., Kozinets, R., \& Shankar, A. (2012). Consumer tribes. Routledge.

Csikszentmihalyi, M. (1997). Finding flow: The psychology of engagement with everyday life. Basic Books.

Debenedetti, A., Oppewal, H., \& Arsel, Z. (2014). Place attachment in commercial settings: a gift economy perspective. Journal of Consumer Research,40(5), 904-923., DOI: $\underline{\text { http://dx.doi.org/10.1086/673469 }}$

Du Gay, P., Hall, S., Janes, L., Madsen, A. K., Mackay, H., \& Negus, K. (2013). Doing cultural studies: The story of the Sony Walkman. Sage.

Dubuisson, S., \& Hennion, A. (1996). Le design : L'objet dans l'usage : la relation objet, usage, usager dans le travail de trois agences [Design: Object in use: the object, use, user relationship in the work of three agencies]. Presses des MINES.

Eckhardt, G. M., \& Bardhi, F. (2016). The Relationship between Access Practices and Economic Systems. Journal of the Association for Consumer Research, 1(2), 210-225. 
Fallan, K. (2008). De-scribing design: Appropriating script analysis to design history, Design Issues, 24(4), 61-75., DOI: 10.1162/desi.2008.24.4.61

Felson, M., \& Spaeth, J. L. (1978). Community Structure and Collaborative Consumption:" A Routine Activity Approach". The American Behavioral Scientist, 21(4), 614.

Findeli, A., \& Bousbaci, R. (2005). L'Eclipse de L'Objet dans les Théories du Projet en Design [The Eclipse of the Object in Design Project Theories], The Design Journa1, 8(3), 3549.

Firat, A. F., \& Venkatesh, A. (1995). Liberatory postmodernism and the reenchantment of consumption, Journal of Consumer Research, 22(3), 239.

Fischer, E., \& Otnes, C. (2006). Breaking new ground: Developing grounded theories in marketing and consumer behavior. Handbook of Qualitative Research Methods in Marketing, 1930.

Fournier, S. (1998). Consumers and their brands: Developing relationship theory in consumer research. Journal of Consumer Research, 24(4), 343-353. DOI: 10.1086/209515

Holt, D. B. (2002). Why do brands cause trouble? A dialectical theory of consumer culture and branding. Journal of Consumer Research, 29(1), 70-90.

INSEE Analyses, Ile-de-France $\mathrm{N}^{\circ} 11 \quad-\quad$ Janvier 2015, available at: http://www.insee.fr/fr/insee_regions/idf/themes/insee-analyses/ina_11/ina_11.pdf

John, N. A. (2013). The social logics of sharing, The Communication Review, 16(3), 113-131., DOI: $10.1080 / 10714421.2013 .807119$

Julier, G. (2014). The culture of design, Sage. 
Kleine, S. S., \& Baker, S. M. (2004). An integrative review of material possession attachment, Academy or Marketing Science Review, 1, 1-29.

Lamberton, C. P., \& Rose, R. L. (2012). When is ours better than mine? A framework for understanding and altering participation in commercial sharing systems. Journal of Marketing, 76(4), 109-125., doi: http://dx.doi.org/10.1509/jm.10.0368

Law, J. (2009). Actor network theory and material semiotics, In B. S. Turner (Ed.) The new Blackwell companion to social theory, p. 141-158, Wiley-Blackwell

Lawson, S. J., Gleim, M. R., Perren, R., \& Hwang, J. (2016). Freedom from ownership: An exploration of access-based consumption. Journal of Business Research, 69(8), 26152623.

Luchs, M., \& Swan, K. S. (2011). Perspective: The Emergence of Product Design as a Field of Marketing Inquiry*, Journal of Product Innovation Management, 28(3), 327-345., DOI: 10.1111/j.1540-5885.2011.00801.x

Magaudda, P. (2011). When materiality 'bites back': Digital music consumption practices in the age of dematerialization. Journal of Consumer Culture, 11(1), 15-36., doi: $10.1177 / 1469540510390499$

McAlexander, J. H., Schouten, J. W., \& Koenig, H. F. (2002). Building brand community. Journal of Marketing, 66(1), 38-54, doi: http://dx.doi.org/10.1509/jmkg.66.1.38.18451

McCracken, G. (1989). Homeyness: A cultural account of one constellation of consumer goods and meanings. Interpretive consumer research, 168-83. 
Mifsud, M., Cases, A. S., \& N'Goala, G. (2015). Service appropriation: how do customers make the service their own? Journal of Service Management, 26(5), 706-725., http://dx.doi.org/10.1108/JOSM-04-2015-0136

Mugge, R., Schoormans, J. P., \& Schifferstein, H. N. (2009). Emotional bonding with personalised products. Journal of Engineering Design, 20(5), 467-476., DOI: $10.1080 / 09544820802698550$

Muniz Jr, A. M., \& O’Guinn, T. C. (2001). Brand community. Journal of Consumer Research, 27(4), 412-432, DOI: 10.1086/319618

Ozanne, L. K., \& Ballantine, P. W. (2010). Sharing as a form of anti-consumption? An examination of toy library users, Journal of Consumer Behaviour, 9(6), 485-498, DOI: $10.1002 / \mathrm{cb} .334$

Park, C. W., Jaworski, B. J., \& Maclnnis, D. J. (1986). Strategic brand concept-image management. The Journal of Marketing, 135-145.

Peck, J., \& Shu, S. B. (2009). The effect of mere touch on perceived ownership. Journal of Consumer Research, 36(3), 434-447. DOI: http://dx.doi.org/10.1086/598614

Pierce, J. L., Kostova, T., \& Dirks, K. T. (2001). Toward a theory of psychological ownership in organizations. Academy of Management Review, 26(2), 298-310. doi: 10.5465/AMR.2001.4378028

Price, J. A. (1975). Sharing: The integration of intimate economies. Anthropologica, 3-27. 
Reckwitz, A. (2002a). The status of the "material" in theories of culture: From "social structure" to "artefacts". Journal for the Theory of Social Behaviour,32(2), 195-217., DOI: $10.1111 / 1468-5914.00183$

Reckwitz, A. (2002b). Toward a theory of social practices: a development in culturalist theorizing. European Journal of Social Theory, 5(2), 243-263., doi: 10.1177/13684310222225432

Richins, M. L. (1994). Special possessions and the expression of material values, Journal of Consumer Research, 21 (3), 522-533.

Rook, D. W. (1985). The ritual dimension of consumer behavior. Journal of Consumer Research, 251-264.

Sahlins, M. (1972). Stone Age Economics. Tavistock, London.

Sartre, J. P. (1943). L'être et le néant. Gallimard, Paris. [Being and Nothingness. Trans. Hazel E. Barnes. New York: Washington Square Press, 1984]

Shove, E., \& Pantzar, M. (2005). Consumers, Producers and Practices Understanding the invention and reinvention of Nordic walking. Journal of Consumer Culture, 5(1), 43-64. doi: $10.1177 / 1469540505049846$

Silverstone, R., \& Haddon, L. (1996). Design and the domestication of ICTs: technical change and everyday life. Communicating by Design: The Politics of Information and Communication Technologies, 44-74.

Silverstone, R., \& Morley, D. (1992). Information and communication technologies and the moral economy of the household. Consuming Technologies: Media and Information in Domestic Spaces. London: Routledge.

Sismondo, S. (2011). An introduction to science and technology studies, John Wiley \& Sons. 
Spiggle, Susan, (1994). "Analysis and interpretation of qualitative data in consumer research." Journal of Consumer Research, 21 (3), 491-503.

Strauss, A. L., \& Corbin, J. M. (1990). Basics of qualitative research (Vol. 15), Newbury Park, CA: Sage.

Thompson, C. J. (1996). Caring consumers: Gendered consumption meanings and the juggling lifestyle. Journal of Consumer Research, 388-407.

Thompson, C. J. (1997), "Interpreting Consumers: A Hermeneutical Framework for Deriving Marketing Insights from the Texts of Consumers' Consumption Stories," Journal of Marketing Research, 34 (November), 438-55.

Tian, K., \& Belk, R. W. (2005). Extended self and possessions in the workplace, Journal of Consumer Research, 32(2), 297-310. DOI: http://dx.doi.org/10.1086/432239

Vial, S. (2015). Que sais-je: Le design [What do I know: Design], PUF, Paris.

Woolgar, S. (1991). The turn to technology in social studies of science. Science, Technology \& Human Values, 16(1), 20-50.

Ziff, B. H., \& Rao, P. V. (1997). Borrowed power: Essays on cultural appropriation. Rutgers University Press. 